\title{
Response of chicken gut bacterial to nutrition and feed additives
}

\begin{abstract}
Chicken gut bacteria play an important role in poultry nutrition with regards to gut health and overall performance of poultry birds. Gut health has currently become an issue of key concern in the poultry industry with the ban on the use of antibiotic growth promoters. The limitation of basic culturing and biochemical techniques may impact on better understanding the response of chicken gut bacteria to feed additives. Although several suitable alternatives to AGPs are available; the knowledge of gut bacteria response to them should be ascertained or studied if not in the light of resistant bacteria strain entering the human food chain. This brings to the fore the fact that such studies will require the combined knowledge of immunology, molecular biology, poultry nutrition and digestive physiology. The most listed response is usually based on competitive exclusion of pathogenic bacteria by beneficial bacteria. The question of how the bacteria cells develop resistance in response to AGP use and what message their DNA is carrying as at when they enter the human food chain needs to be answered. May be the bacteria have silent messengers which tell them when to metamorphose into adaptable strain when the odds are against them. Or are answers in the "details" of how they physiologically respond to other feed additives in the absence of AGP.
\end{abstract}

Keywords: antibiotic growth promoters, feed additives, gut bacteria, molecular techniques, poultry nutrition
Volume 2 Issue 4 - 2017

\section{Ofongo- Abule Ruth TS}

Department of Animal Science, Niger Delta University, Nigeria

Correspondence: Ruth TS, Department of Animal Science, Niger Delta University, PMB O7I Wilberforce Island, Bayelsa State, Nigeria, Tel +2348I58683316, Email tariruth@live.de

Received: June 26, 2016 | Published: September 21, 2017
Abbreviations: AGPs, antibiotic growth promoters; GALT, gut associated lymphoid tissues; DNA, deoxyribonucleic acid; E. coli, escherichia coli

\section{Introduction}

The issue of gut health in relation to gut bacterial became more evident with the ban of antibiotic growth promoters (AGPs) in animal/poultry nutrition. This ban became preeminent with the development of resistant bacteria strain getting into the food chain. This will ultimately result in bacteria related health issues for consumers of poultry product. In the poultry industry, gut health is not just an interaction between gut bacteria; nutrients provided by the diet (nutrition) and the gut itself as a digestive organ but also as an organ that provides adequate protection against pathogenic bacteria. Gut associated lymphoid tissues (GALT) provides protection against pathogens encountered by the gut in chicken. ${ }^{1}$ It is responsible for inducing immune response against bacteria, viral, and parasitic enteric (i.e. introduced via the digestive tract) antigens $\mathrm{s}^{2-4}$ as well as responses to innocuous antigens. ${ }^{5}$

All this said: how do the bacterial populations that of a "MUST" must attach to the intestinal wall respond to certain feed additives used as suitable/probable alternatives to AGPs? It is a known fact that gut health has a principal role in determining overall health and performance of poultry birds. Immune response based studies will indicate the bird response. However bacteria response studies do consider the principles or mode of action of these alternatives with regards to bacteria population in the gut. Also considered is bird performance in terms of weight gain, feed conversion ratio/feed: gain ratio and coefficient of nutrient digestibility. Nutrient digestibility is with reference to the specific nutrient in question which is most likely affected. Modes of action of these alternatives differ, results from different studies utilizing them may also differ but, the core issue of bird performance being improved is of utmost importance to the farmer. Be as it may, bacteria population are more often determined using basic culturing and biochemical method of plating specific bacteria for stipulated number of days.

Although there are suitable alternatives to AGPs (Enzymes, Probiotics, Prebiotics, Acidifiers, Synbiotic products etc), however how their effect on the biodiversity of gut bacteria may be an issue of consideration. Due to lack of knowledge of appropriate culturing conditions, large number of bacteria may remain unidentified using basic culturing and biochemical techniques have resulted in the misclassification of some of these bacteria. ${ }^{6}$ Given the profound impact of gut bacteria on performance, identification of bacteria assemblages in the gut at random will be of high biological and economic importance. ${ }^{7-10}$ Considering the limitation of standard culturing methods, a study was carried out aiming to identify bacteria biodiversity amplified from the gut of broiler birds through molecular techniques using 165 bacteria DNA sequencing. In using the 165 DNA sequencing, consideration was given to the treatment or type of feed additive the birds' were subjected to (Non-starch polysaccharide degrading enzyme and an AGP - (antibiotic). With these two factors as treatment basis, the molecular technique earlier mentioned was used to identify the bacteria collected from ileal digesta samples when the broilers were six weeks old. From the result of that study, ${ }^{11}$ the relative number of bacteria identified indicated a high number (48) of Escherichia coli (E. coli) and rather low (1) number of Lactobacillus acidophilus with AGP administration. Enzyme supplementation on the other hand resulted in a numerically higher (5) Lactobacillus acidophilus and consequently lower (9) E. coli number in compared to AGP administration.

As earlier stated results from several studies differ with regards to 
bird response and recorded gut bacteria counts. In the light of already mentioned limitation of basic standard culturing methods for bacteria, the principle of "competitive exclusion" with regards to beneficial bacteria against pathogenic bacteria when suitable alternatives to AGPs are utilized has consistently proven positive in most studies. In as much as this is so, the response of the bacteria with respect to their physiology, metabolism, DNA and other factor which may not be obviously evident should be of concern. As the saying goes "water will always find its level". If the bacteria develop resistance with continuous use of AGPs, (invariably their DNA is metamorphosing); then what message is the DNA receiving and metamorphosing into when other alternatives are used? What does their DNA message carry when it enters the human food chain? These are questions that need answers and the answers cannot be found in isolation.

\section{Conclusion}

In conclusion, there are poultry diseases directly influenced by gut health and there are also poultry diseases indirectly influenced by gut health. If gut health revolves around nutrient bioavailability in the gut and its interaction with gut bacteria, then may be the answer to these questions is in the "DETAILS"

\section{Acknowledgements}

The author gratefully acknowledges TETFUND (Tertiary Education Trust Fund) for the grant given to the author for the molecular identification study. ${ }^{11}$

\section{Conflict of interest}

The author in no way has direct or indirectly endorsed or disrepute any poultry research work carried out using feed additives mentioned in this article or companies that produce them. Everything written is the personnel opinion of the author regarding issues discussed and stands to be corrected where appropriate.

\section{References}

1. Sklan D. Early gut development: the interaction between feed, gut health and Immunity. In: Tucker LA, Taylor- Pickard JA editors. 1st ed. Interfacing Immunity, gut health and performance. UK: Nottingham University press; 2004. p. 1-117.

2. Muir WI, Bryden WL, Husband AJ. Immunity, Vaccination and the avian intestinal tract. Dev Comp Immunol. 2000;24(2-3):325-342.

3. Kajiwara E, Shigeta A, Horiuchi H, et al. Development of Peyers Patche and caecal tonsil in gut - associated lymphoid tissues in the chicken embryo. J Vet Med Sci. 2003;65(5):607-614.

4. Yasuda M, Tanaka S, Arakawa H, et al. A comparative study of gut associated lymphoid tissue in calf and chicken. Anato Rec. 2002;266(4):207217.

5. Klipper E, Sklan D, Fredman A. Immunie response of chickens to dietary protein antigens. Vet Immu and Immu path. 2000;74:209-223.

6. Tellez G, Higgins S, Donoghue A, et al. Digestive physiology and the role of micro organisms. J Appl Poult Res. 2006;15:136-144.

7. Ezenwa V, Gerardo N, Inunye D, et al. Animal behavior and the microbiome. Science. 2012;338(6104):198-199.

8. Apajalathi J, Kettunen A, Graham H. Characteristics of the gastrointestinal microbial communities with specific relevance to the chicken. $J$ Worlds Poult Sci. 2004;60:226-232.

9. Apajalathi J, Kettunen A, Bedford MR, et al. Precent $\mathrm{G}+\mathrm{C}$ profiling accurately reveals diet related differences in the gastrointestinal microbial community of broiler chickens. Appl Envi Microb. 2001;67:5656-5667.

10. Apajalthi J, Bedford MR. Improved bird performance by feeding its microflora. World's poult Sci J. 1999;15:20-23.

11. Ofongo-Abule, R TS, Etebu E, et al. Performance and molecular identification of bacteria isolated from the gut of broiler birds after antibiotic administration and enzyme supplementation. J Micro Biotech Food Sci. 2016;6(3):924-929 